\title{
Membrane Hsp70-supported cell-to-cell connections via tunneling nanotubes revealed by live-cell STED nanoscopy
}

\author{
Judith Reindl ${ }^{1}$ - Maxim Shevtsov ${ }^{2,3,4,5} \cdot$ Günther Dollinger $^{1} \cdot$ Stefan Stangl $\left.\right|^{2} \cdot$ Gabriele Multhoff $^{2}$
}

Received: 16 October 2018 / Revised: 19 November 2018 / Accepted: 3 December 2018 / Published online: 10 January 2019

(C) The Author(s) 2018

\begin{abstract}
Heat shock protein Hsp70 (Hsp70) is found on the cell surface of a large variety of human and mouse tumor cell types including U87, GL261 glioblastoma, and 4T1 mammary carcinoma cells. We studied the role of membrane-bound Hsp70 (mHsp70) in the formation of cell-to-cell connections via tunneling nanotubes (TNTs) using live-cell STED nanoscopy. This technique allows the visualization of microstructures in the 100-nm range in the living cells. We could show that the presence of tumor-derived mHsp70 in TNTs with a diameter ranging from 120 to $140 \mathrm{~nm}$ predominantly originates from cholesterol-rich-microdomains containing the lipid compound globoyltriaosylceramide (Gb3). Under non-stress conditions, Hsp70 and Gb3 are structurally clustered in the membrane of TNTs of tumor cells that showed tumor type specific variations in the amount of cell-to-cell connection networks. Furthermore depletion of cholesterol and ionizing radiation as a stress factor results in a complete loss of Hsp70-containing TNTs.
\end{abstract}

Keywords Membrane-bound Hsp70 · Live-cell STED · Tunneling nanotubes $\cdot$ Cell-to-cell connection $\cdot$ Cellular networks

\section{Introduction}

Heat shock proteins (HSPs) with a molecular weight of approximately $70 \mathrm{kDa}$ constitute to a large family of highly conserved proteins that are involved in protein homeostasis, cell proliferation, differentiation, and carcinogenesis (Shevtsov and Multhoff 2016; Hartl and Hayer-Hartl 2002; Mayer and Bukau 2005). Apart from its cytosolic overexpression, the highly stress-inducible member Hsp70 (HSPA1A) is frequently found on the cell membrane in a large variety of different tumor types (Thorsteinsdottir et al. 2017; Multhoff

Judith Reindl and Maxim Shevtsov contributed equally to the Ms.

Electronic supplementary material The online version of this article (https://doi.org/10.1007/s12192-018-00958-w) contains supplementary material, which is available to authorized users.

Judith Reindl

judith.reindl@unibw.de

Gabriele Multhoff

gabriele.multhoff@tum.de

1 Universität der Bundeswehr München, Werner-Heisenberg-Weg 39, 85577 Neubiberg, Germany et al. 1995). The presence of Hsp70 on the plasma membrane of tumor cells was determined by global profiling of membrane proteins (Shin et al. 2003) and flow cytometry using cmHsp70.1 monoclonal antibody (Stangl et al. 2011; Multhoff et al. 1995) that specifically detects a conformational epitope of Hsp70 in the context with lipids. Analysis of the lipid composition of membrane Hsp70-positive (mHsp70) tumor cells revealed that globoyltriaosylceramide $(\mathrm{Gb} 3)$, which is residing in cholesterol-rich microdomains of tumor but not normal cells, serves as a potential binding partner for $\mathrm{mHsp} 70$ (Gehrmann et al. 2008; Simons and Toomre 2000;
2 Center for Translational Cancer Research (TranslaTUM), Klinikum rechts der Isar, Technischen Universität München (TUM), Ismaningerstrasse 22, 81675 Munich, Germany

3 Institute of Cytology of the Russian Academy of Sciences (RAS), Tikhoretsky ave. 4, St. Petersburg 194064, Russia

4 Pavlov First Saint Petersburg State Medical University, L'va Tolstogo str. 6/8, St. Petersburg 197022, Russia

5 Polenov Russian Scientific Research Institute of Neurosurgery, Mayakovskogo str. 12, St. Petersburg 191104, Russia 
Nimmervoll et al. 2015). Apart from its documented immunological relevance as a tumor-specific biomarker for antibody- (Stangl et al. 2001) and NK cell-based-targeted therapies (Specht et al. 2015), the role of $\mathrm{mHsp} 70$ is poorly understood. The formation of tunneling membrane nanotubes (TNTs) that enable connections between living neighboring tumor cells under non-stress conditions could be determined as a novel function for $\mathrm{mHsp} 70$ by live-cell STED nanoscopy.

Tunneling nanotubes (TNTs) that are supposed to mediate unidirectional, actin-dependent vesicle and organelle transport (Marzo et al. 2012) were firstly described by Rustom and coworkers (Rustom et al. 2004) in rat brain tumor cells. Apart from cancer cells, TNTs were also identified in prion- or virally infected cells (Ariazi et al. 2017; Sherer 2013), healthy endothelial and immune cells, and neurons to support cell-cell communication (Marzo et al. 2012; Watkins and Salter 2005; Koyanagi et al. 2005; Önfelt et al. 2006). Calcium signaling (Sowinski et al. 2008), mitochondria (Vignais et al. 2017), mRNA (Haimovich et al. 2017), and exosomal transports (Dupont et al. 2018) have been found to be mediated by TNTs. Additionally, therapy resistance of malignant gliomas has been associated with the presence of TNTs (Weil et al. 2017), and large tubular networks have been found to be involved in tumor cell proliferation and invasion (Osswald et al. 2015).

The length of TNTs varies from a few micrometers up to several cell diameters, and the diameter of TNTs ranges between 50 and $200 \mathrm{~nm}$ (Rustom et al. 2004). Many publications report on stress-inducible formations of TNTs with a main transport direction from a stressed, TNT-forming cell to a non-stressed recipient cell (Marzo et al. 2012).

Due to the small diameters of TNTs, most structural analysis has been performed by SEM or TEM electron microscopy (Lou et al. 2017) with fixed, non-viable cells. Therefore, only static but not dynamic cellular processes can be monitored. Live-cell imaging using conventional optical microscopy is limited in resolution by the abbe limit $(\sim 200-250 \mathrm{~nm})$ and therefore detailed structural analysis of the composition of nanotubes is impossible.

Herein, we report on live-cell super-resolution, gated STED nanoscopy (Hell and Wichmann 1994; Vicidomini et al. 2011; Bottanelli et al. 2016) with a sub-diffraction resolution of $<100 \mathrm{~nm}$ which allows a more detailed analysis of substructures of TNTs in viable tumor cells under physiological culture conditions.

Human and mouse glioblastoma (U87, GL261) and mouse mammary (4T1) carcinoma cells show a highly structured, dotted pattern of mHsp70 in Gb3-containing cholesterol-rich microdomains after staining with fluorescence-labeled cmHsp70.1 and Gb3 antibodies, as determined by conventional light microscopy (Gehrmann et al. 2015). To study the role of mHsp70 in the formation of cell-to-cell connections via nanotubes, we performed high-resolution live-cell STED nanoscopy. By quantitative size measurements and network analysis, a detailed insight in the structural and functional clustering of mHsp70 and Gb3 in TNTs could be determined in different cancer cell lines under physiological culture conditions to get a deeper insight in the tumor cell communication.

\section{Methods}

\section{Cell lines}

Human U87 (ATCC, HTB-14) glioma, mouse GL261 (ATCC, CRL-1887) glioma, and mouse 4T1 (ATCC, CRL-2539) mammary carcinoma cell lines were grown at $37{ }^{\circ} \mathrm{C}$ in RPMI-1640 cell medium supplemented with $10 \%$ fetal bovine serum (FBS), 2 mM L-glutamine and antibiotics (100 units $/ \mathrm{ml}$ Penicillin $\mathrm{G}$ and $100 \mu \mathrm{g} / \mathrm{ml}$ streptomycin). Cell lines were regularly tested negative for mycoplasma contamination. Cells were passaged twice a week, and single-cell suspensions were derived by short-term (less than $1 \mathrm{~min}$ ) treatment with $0.25 \%(w / v)$ trypsin, $0.53 \mathrm{mM}$ EDTA.

\section{Flow cytometry}

The expression of the membrane-bound Hsp70 on the tumor cells was determined by flow cytometry using either the FITC-conjugated cmHsp70.1 mAb (IgG1; multimmune $\mathrm{GmbH}$ ), which is directed against the extracellular-exposed sequence of membrane Hsp70. Briefly, after incubation of viable cells $\left(0.3 \times 10^{6}\right.$ cells $)$ with the primary antibodies for 30 min at $4{ }^{\circ} \mathrm{C}$ and following two washing steps, 7-AAD viable cells were analyzed using a FACSCalibur flow cytometer (BD Biosciences). An isotype-matched $\left(\operatorname{IgG}_{1}\right)$ control antibody was used to determine non-specific binding to cells.

\section{Methyl- $\beta$-cyclodextrin treatment}

Ten millimolars of the cholesterol-depleting agent methyl- $\beta$ cyclodextrin $(\mathrm{MbC})$ which is known to be non-lethal was added to the cells. Directly after adding image acquisition with a rate of 1 image per 2 min was started.

\section{Immunofluorescence staining}

Cells $\left(1 \times 10^{6}\right.$ cells $\left./ \mathrm{ml}\right)$ were allowed to settle on non-coated glass dishes (IBIDI, Munich, Germany) and stained with cmHsp70.1-FITC mAb (1:250) (multimmune, Munich, Germany) for $30 \mathrm{~min}$ and then imaged using a TCS SP8 STED $\times 3$ microscope (Leica, Germany). Isotype-matched $\mathrm{IgG}_{1}$ antibodies conjugated to FITC (Sigma, USA) were used as a control. For the visualization of the plasma membrane, 
PKH and CellVue ${ }^{\circledR}$ Fluorescent Cell Linker Kits (SigmaAldrich, USA) providing fluorescence labelling of live cells were applied according to manufacturer's protocol. For the detection of the globoyltriaosylceramide (Gb3), Alexa Fluor 555-conjugated cholera toxin B subunit (Molecular Probes Europe BV) was used at a dilution of 1:10.

\section{STED microscopy, image processing, and depiction}

The glass dishes were placed on the TCS SP8 STED $\times 3$ microscope, which was temperature-controlled to $23{ }^{\circ} \mathrm{C}$, as described before (Reindl et al. 2015) to avoid drift throughout the image acquisition and to ensure refractive index match between the glass slide, cells, and immersion medium. Images were acquired using $\times 100$ objective (Leica HCX PL APO $\times 100 / 1.4$ Oil). FITC labelling was imaged using $495 \mathrm{~nm}$ excitation laser and 592-nm STED depletion laser. The detection range was $500-538 \mathrm{~nm}$. Alexa 555 staining was imaged using 550-nm excitation and 660-nm depletion with a detection range from 575 to $630 \mathrm{~nm}$. Gating in both channels was from 0.3 to $6 \mathrm{~ns}$; no line averaging and accumulation were performed. All samples were acquired in $z$-stacks with a distance of $250 \mathrm{~nm}$ and a pixel size of $50 \mathrm{~nm}$ where each $z$-slice was imaged in both color channels before moving to the next slice. $Z$-stacks were deconvolved using the Huygens software (SVI). Resolution was measured as the full width at half maximum of the smallest labeled spots and was $97 \pm 5 \mathrm{~nm}$. All images show maximum projections.

\section{Sample size determination and errors}

The imaging for network quantification and Hsp70 thickness measurements was performed twice for 4T1 and GL261 and three times for U87. The membrane measurement was performed only in 4T1 cells and replicated once, as the lipid raft measurements for U87. In this study, the single cells are considered to be independent samples. This is also supported by the fact that the variances are equal in the experiment replications, which allowed for pooling of data for each cell line. Cell numbers for each experiment are depicted in Table 1. The standard deviation for the string thickness measurement is approx. $\sigma=20 \mathrm{~nm}$ in the worst case (GL261). The sample size, i.e., the minimum number of analyzed cells, is calculated as $n=\left(\frac{2 \times c \times \sigma \times t}{L}\right)^{2}$, with the width of the confidence interval $L$ and the $t$ and c factors (Kreyszig 1974). The confidence interval of $90 \%$ leads to $c=1.645$ and $t=1.337$, which has to be used as small sample sizes are taken. A confidence interval of $L<30 \mathrm{~nm}$ as $1 / 6$ of the string thickness leads to a sample size of $n=9$ and $n=10$, respectively. Therefore, the used sample sizes of each experiment are supposed to be sufficient. For thickness measurements, the standard error of the mean (SEM) was used.

For network quantification, the experiments were pooled and the error occurs due to counting and is calculated according to the Poisson statistics as $\frac{1}{\sqrt{n}}$.

\section{Results}

\section{Clustering of mHSP70 at TNTs}

STED imaging was performed in two to three independent experiments with a total number of 55 4T1, 33 GL261, and 81 U87 tumor cells. The sample size was sufficient for statistical analysis, as described in the "Methods" section.

For visualization of mHsp70 in GL261, U87, and 4T1 tumor cells, the fluorescein isothiocyanate (FITC)-conjugated monoclonal antibody (mAb) cmHsp70.1 was used for analysis. This antibody recognizes an epitope of the C-terminal domain of Hsp70 that is exposed to the extracellular milieu (Stangl et al. 2011) of viable tumor cells. Binding affinities of cmHsp70.1 mAb to Hsp70 as determined in solution using microscale thermophoresis analysis revealed $\mathrm{K}_{\mathrm{D}}$ values in lower nanomolar range (Stangl et al. 2018). All three tumor cell lines GL261, U87, and 4T1 were strongly positive for mHsp70 as determined by flow cytometry (Fig. 1a) and showed a typical dotted staining pattern of $\mathrm{mHsp} 70$ (green) on the plasma membrane, as determined by immunofluorescence studies. In addition to the membrane localization, Hsp70 was found in strings that are connecting neighboring GL261 (Fig. 1b), U87 (Fig. 1c), and 4T1 (Fig. 1d) tumor cells.

In contrast to cmHsp70.1 mAb, a FITC-conjugated $\mathrm{IgG}_{1}$ isotope-matched control antibody did not exhibit any specific staining of TNTs in GL261 tumor cells (Supplementary
Table 1 Cell numbers of the single experiments

\begin{tabular}{llllll}
\hline Cell line & Experiment 1 & Experiment 2 & Experiment 3 & Experiment 4 & total \\
\hline 4T1 & 43 & - & 12 & - & 55 \\
GL261 & 23 & 10 & - & - & 33 \\
U87 & 32 & 14 & - & 35 & 81 \\
\hline
\end{tabular}

Experiments 1 and 2 show the results of a staining with cmHsp $70.1 \mathrm{mAb}$, experiment 3 that of a double staining using cmHsp70.1 mAb and PKH, and experiment 4 that of a double staining with cmHsp70.1 mAb and Gb3 antibody 


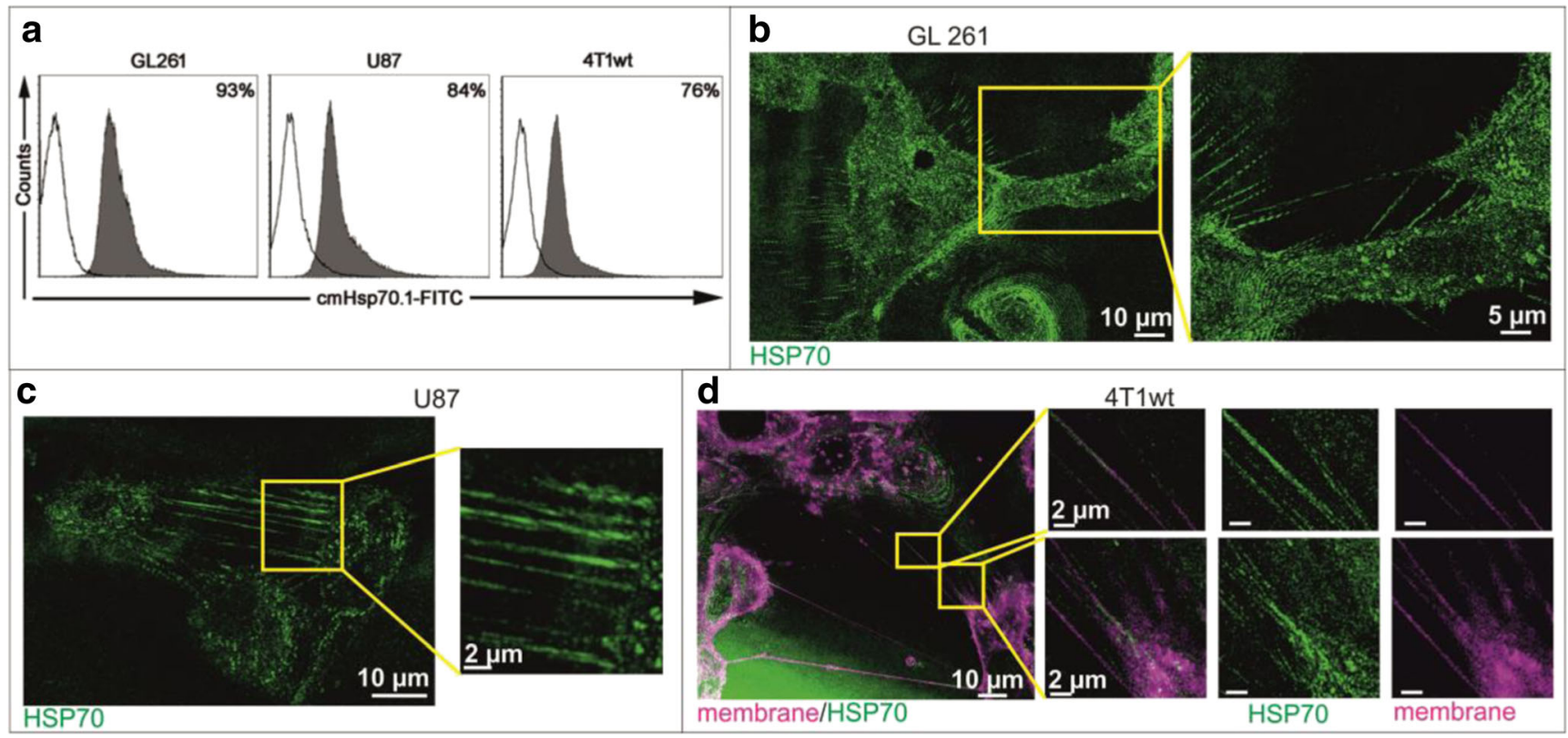

Fig. 1 Representative flow cytometric analysis of the $\mathrm{mHsp} 70$ expression on GL261, U87, and 4T1 tumor cells (a). The proportion of positively stained cells is indicated in each graph. Hsp70 (green) is localized on the plasma membrane and in TNTs of GL261 (b), U87 (c), and 4T1 (d) tumor

Figure 1). Presently, studies are ongoing to test a FITC-labeled Hsp70-reactive peptide (TPP) (Stangl et al. 2014) instead of cmHsp70.1 mAb for staining TNTs. Co-staining of viable 4T1 cells with the membrane tracking dye PKH (Spötl et al. 1995) (magenta) and FITC-labeled cmHsp70.1 mAb (green) confirms that Hsp70 is localized in the plasma membrane and in nanotubes derived thereof (Fig. 1d). A one-to-one correlation of Hsp70 and membrane stained tunneling nanotubes (TNTs) cells that are connecting neighboring tumor cells. Membranes of the tumor cells are delineated by co-staining with the PKH tracking dye (magenta) (d)

is shown in Figs. 1d and 2a. This correlation was determined by scoring all connecting nanotubes in a total of 35 U87 and $124 \mathrm{~T} 1$ cells that show TNTs with both staining reagents.

Treatment of U87 and GL261 cells with a non-lethal concentration of methyl- $\beta$-cyclodextrin $(\mathrm{MbC}, 10 \mathrm{mM})$ which can deplete cholesterol from the lipid bilayer and thereby dissociates cholesterol-richmicrodomains results in a loss of Hsp70 from lipid rafts and dissociates Hsp70-containing

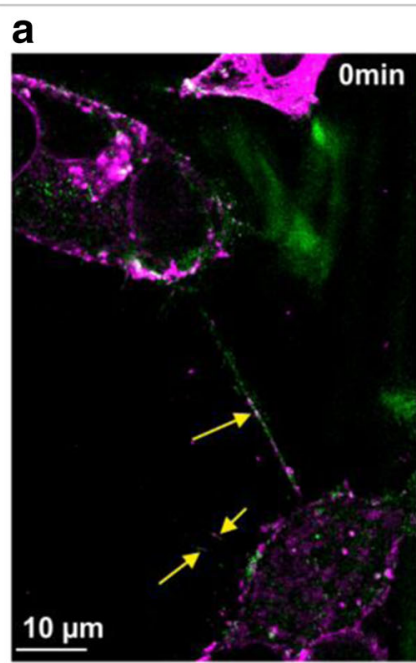

membrane/HSP70

Fig. 2 Treatment with methyl- $\beta$-cyclodextrin $(\mathrm{MbC})$ results in a depletion of cholesterol, loss of Hsp70 from the plasma membrane, and a dissociation of TNTs in U87 (a) and GL261 cells (b) within 4 min. The

\section{b}
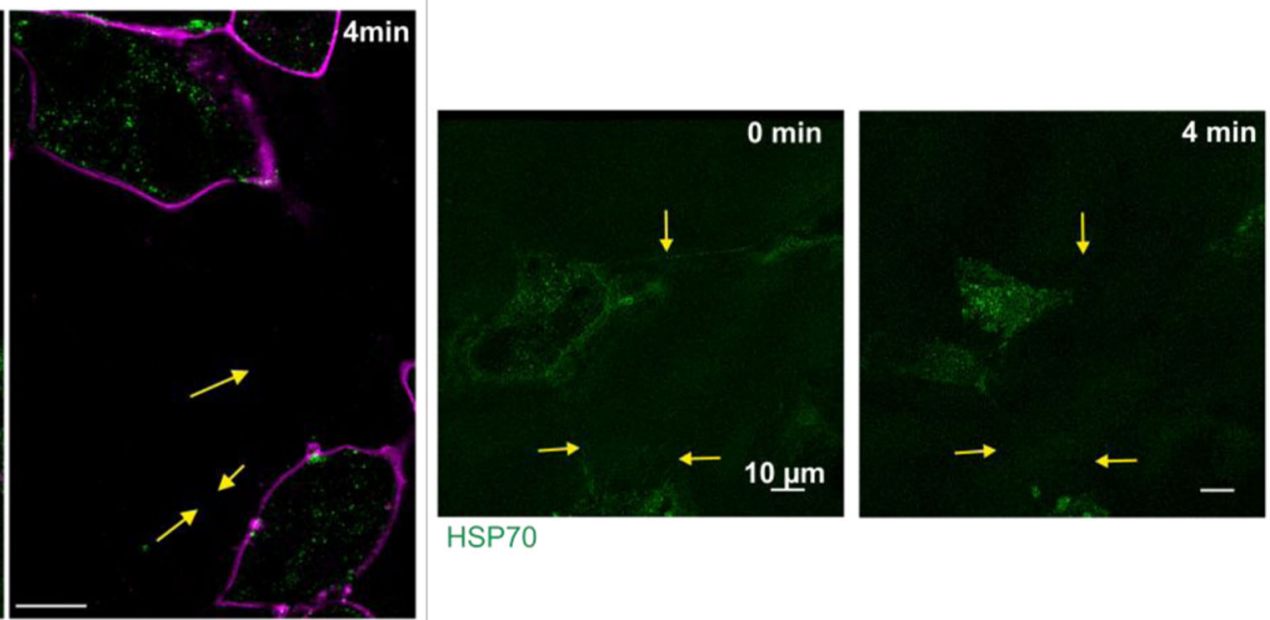

HSP70

dissociation of TNTs upon MbC treatment is more rapid in U87 compared to GL261 tumor cells 
Table 2 Diameters of Hsp70-, PKH-, and Gb3stained TNTs in 4T1, GL261, and U87 cell lines

\begin{tabular}{lll}
\hline Cell line & Staining & Diameter $(\mathrm{nm})$ \\
\hline 4T1 & Hsp70 & $126 \pm 5$ \\
GL261 & Hsp70 & $241 \pm 9$ \\
U87 & Hsp70 & $137 \pm 14$ \\
4T1 & PKH & $168 \pm 4$ \\
U87 & Gb3 & $136 \pm 13$ \\
\hline
\end{tabular}

The resolution in this assay was $97 \pm 5 \mathrm{~nm}$. The data represent mean values and the standard error of the mean (SEM)
TNTs that mediate cell-to-cell communications. In U87 cells, 4 min after incubation with a non-lethal dose of MbC, Hsp70 completely disappeared from the plasma membrane and Hsp70-containing nanotubes dissociated (Fig. 2a). As shown in the same figure, the relocation of $\mathrm{mHsp} 70$ from the membrane to the interior of the cell and the depletion of the TNTs are much faster than the disintegration of the outer cellular membrane. Similar results are observed in GL261 cells with a slightly slower kinetic (Fig. 2b).

\section{Size measurements of Hsp70-, PKH-, and Gb3-stained TNTs}

The length of Hsp70-containing nanotubes ranges from a few micrometers up to $>100 \mu \mathrm{m}$ which is equivalent to several cell diameters. The diameter of TNTs was determined by using the autocorrelation function, as previously described by Reindl et al. (2017) in detail. Briefly, the autocorrelation function (ACF) for each tube is determined. As the intensity distribution in the short dimension of the TNTs can be approximated by a Gaussian function, the full width at half maximum of the ACF directly gives the thickness of the TNT multiplied by factor of $\sqrt{2}$. The results of these measurements summarized in Table 2 show similar diameters for Hsp70-containing TNTs in 4T1 $(126 \pm 5 \mathrm{~nm}, \mathrm{SEM})$ and U87 $(137 \pm 14 \mathrm{~nm}, \mathrm{SEM})$ cells, and significantly larger diameters $(p=0.04$, onesided, unpaired $t$ test) in GL261 cells $(241 \pm 9 \mathrm{~nm}$, SEM). All measured diameters are larger than the resolution of $97 \pm 5 \mathrm{~nm}$.

The diameter of PKH-stained TNTs of 4T1 cells (168 \pm $4 \mathrm{~nm}(\mathrm{SEM})$ ) was comparable to that of the Hsp70-stained TNTs. A more detailed view to the staining pattern of PKHand cmHsp70.1 mAb-stained TNTs revealed no detailed correlation within a size regime of $100 \mathrm{~nm}$, as visible in the inserts in Fig. 1d, where nearly no white signals that indicate an overlap between green and magenta is visible in the tubes consisting of Hsp70 and PKH. The staining pattern of lipid raft (Gb3)- and Hsp70-stained TNTs in U87 cells (Fig. 3) exhibited identical sizes and a similar clustering of both markers in close proximity, within the TNTs (insert in Fig. 3).

\section{Model of HSP70 and Gb3 clustering in TNTs}

The acquired imaging data and the quantification of the TNTs allowed us to propose the following model that describes the structure of mHSP70 and Gb3 positive TNTs. Figure 4 shows a schematic representation of a total magnification of 130 ( $\times 13$ imaging magnification, $\times 100$ objective magnification) of a representative region of a TNT in U87 cells. Although labelling of both structures is present throughout the whole TNT, no co-

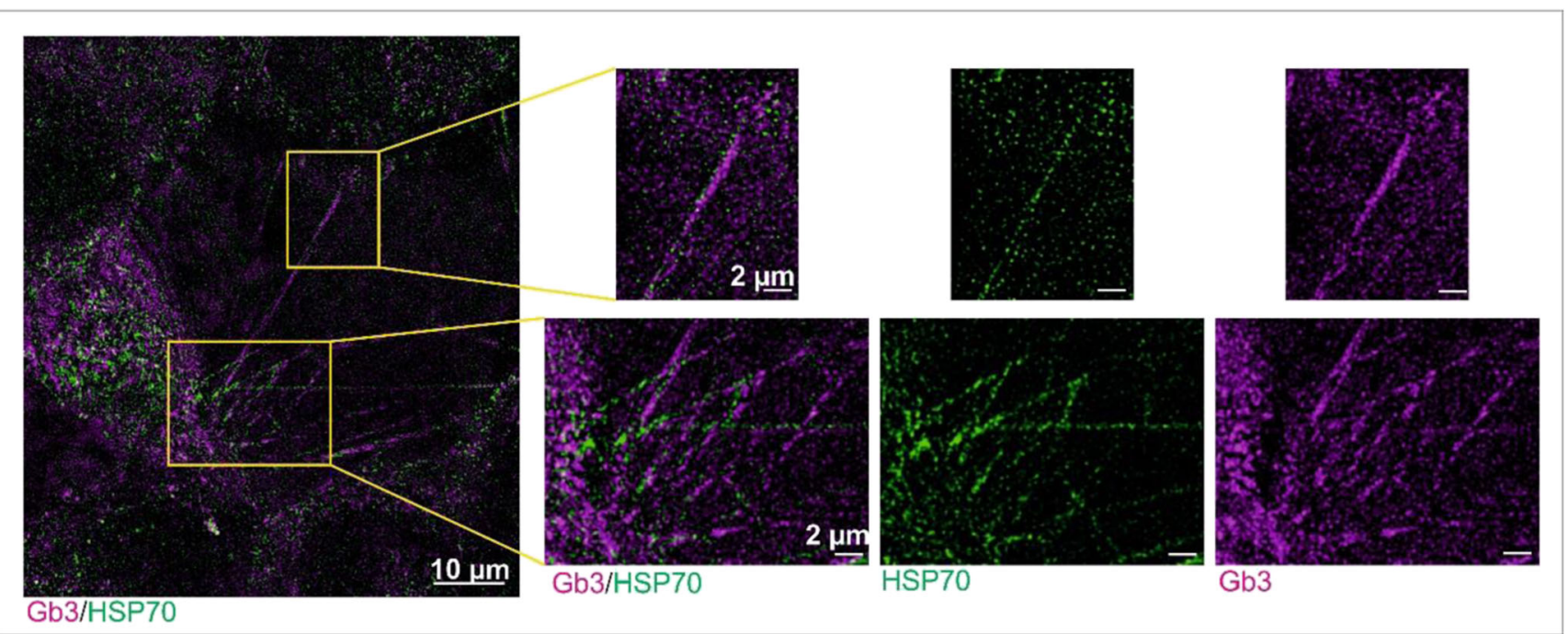

Fig. 3 U87 cells co-stained with cmHsp70.1 (green) and Gb3 (magenta) antibodies show that both markers are in close proximity within the nanotubes. At a resolution of $100 \mathrm{~nm}, \mathrm{Hsp} 70$ and $\mathrm{Gb3}$ are not co-localizing along the string 


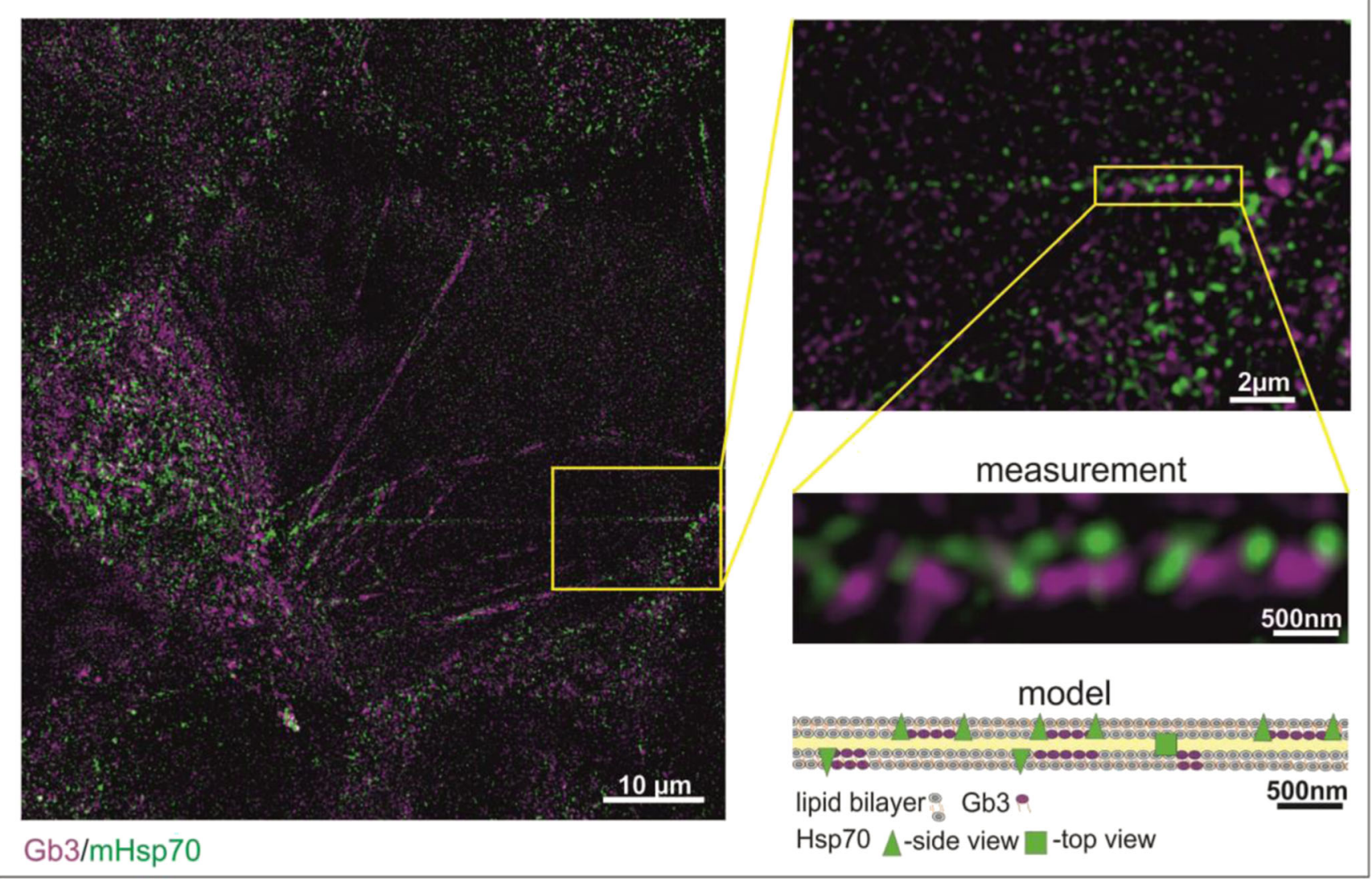

Fig. 4 STED microscopy-based model of the organization of Gb3 (magenta) and Hsp70 (green) in TNTs at a $\times 13$ imaging magnification

localization is visible within the resolution of $100 \mathrm{~nm}$. Throughout the whole length of the TNT, Hsp70 indicated in green alternates with Gb3 in magenta and no overlapping regions are visible (no white regions). This clustering of Hsp70 and Gb3 is resembled also in cholesterol-rich microdomains of tumor cell membranes (Gehrmann et al. 2008).

\section{Quantification of TNT network connection types}

Although the absolute number of TNTs per cell differed drastically within one cell line, the type of network connections appeared to be specific for an individual cell line. The following three major connection categories could be distinguished: "no connecting networks," "simple network connections" between two cells, and "complex network connections" between two or more cells. The different network types (no, simple, complex network connections) were quantified in the different tumor cell types (Fig. 5). The majority of 4T1 tumor cells $(71 \pm 12 \%)$ showed no network connections ( $p<0.05$, one-sided, unpaired $t$ test), $24 \pm 7 \%$ simple and $5 \pm 3 \%$ of the $4 \mathrm{~T} 1$ cells complex network connections. In contrast, GL261 cells predominantly revealed complex $(52 \pm 13 \%)$ network connections ( $p<0.05$, one-sided, unpaired $t$ test), $12 \pm$ $7 \%$ simple, and $36 \pm 11 \%$ of the GL261 cells revealed no network connections, and $44 \pm 7 \%$ of the U87 cells showed no, $35 \pm 7 \%$ simple, and $20 \pm 6 \%$ complex network connections.

\section{Discussion}

In this study, the role of mHsp70 in the formation of cellto-cell connections via TNTs was studied in three different tumor cell lines under physiological 2D cell culture conditions using super-resolution, live-cell STED nanoscopy. Due to technical limitations of the STED nanoscopy system, the measurements were performed at room temperature and not at $37{ }^{\circ} \mathrm{C}$. These conditions are not perfect, but tumor cells stayed in the physiological culture medium alive during the whole experimental procedures. Further developments are ongoing to adopt the nanoscopy system to a temperature of $37^{\circ} \mathrm{C}, 3 \mathrm{D}$ cell culture models, and animal models.

In general, Hsp70 was present in all TNTs of all three cell lines, as determined at a resolution of $100 \mathrm{~nm}$. Hsp70 that clusters in TNTs originates from cholesterol-rich 
Fig. 5 Characterization of the major three categories of nanostring network connections (no, simple, complex network connections) in 4T1 (dark gray), GL261 (light gray), and U87 (black) tumor cells

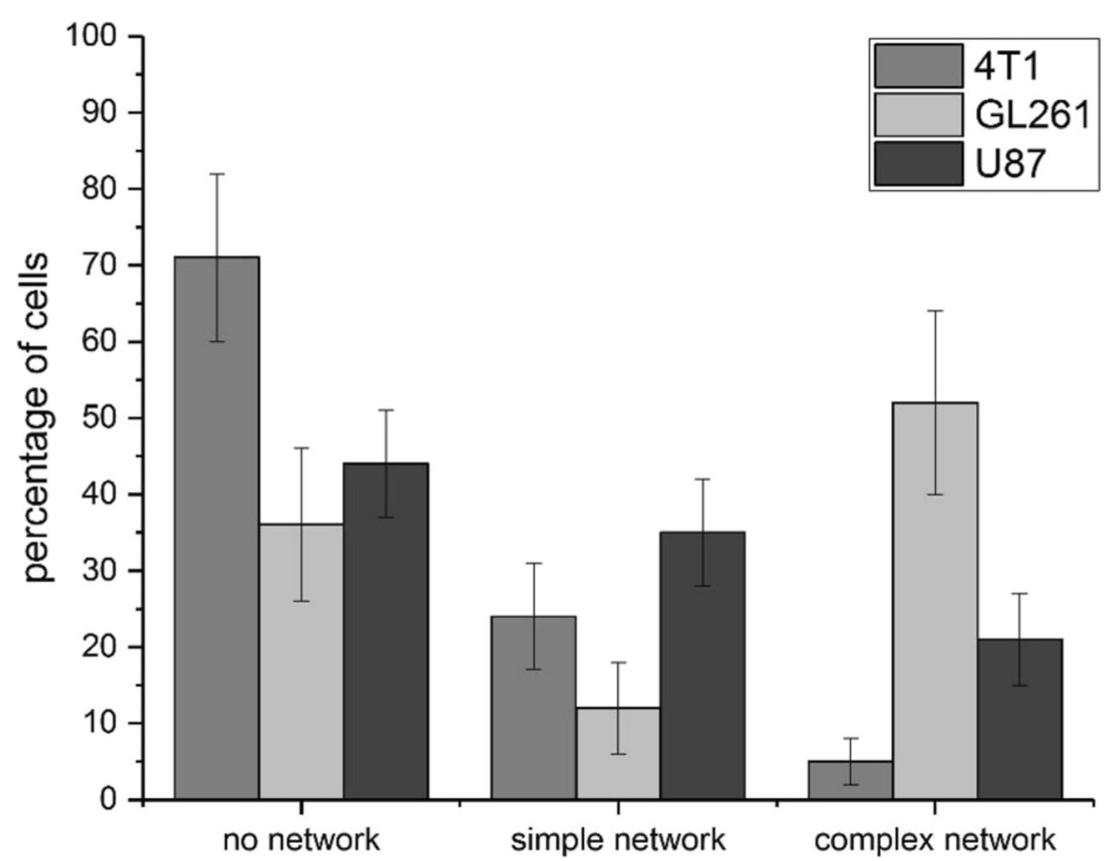

microdomains containing Hsp70, cholesterol, and Gb3. The measured diameter of Hsp70-based TNTs in different tumor cell types ranged between 120 and $240 \mathrm{~nm}$ which is comparable to that of published data showing an average diameter of $50 \mathrm{~nm}$ to $200 \mathrm{~nm}$ for nanotubes (Rustom et al. 2004). A more detailed analysis of the clustering of Hsp70 and Gb3 in living tumor cells revealed a close proximity of both markers in the plasma membrane Hsp70 (Multhoff and Hightower 2011) and TNTs. We therefore propose a model of the clustering of mHsp70 and Gb3 within the TNTs, which can be expanded to any other structures clustered at or in TNTs. This provides the first basis to understand the structural protein and lipid composition of TNTs.

Furthermore, we characterized the network formation complexity, which appeared to be cell-type specific. GL261 cells form more complex cellular networks than U87 and 4T1 tumor cells that also showed differences in their cell-to-cell communication networks. We hypothesize that the capacity of a tumor cell to form intracellular networks might impact on important hallmarks of cancer (Hanahan and Weinberg 2011) such as proliferation, migration, and invasiveness, which was also shown by Osswald et al. (2015). Therefore, in the future, live-cell imaging might provide a useful tool to characterize cellto-cell communications among tumor cells or tumor cells with cells of the tumor microenvironment.

In contrast to previously published work (Marzo et al. 2012), the formation of Hsp70-based TNTs appears to be independent of environmental stress. Moreover, we could demonstrate that ionizing irradiation as a stress factor results in a complete loss of tumor-derived TNTs
(Supplementary Figure 2). One might speculate that following stress, Hsp70 retranslocates from TNTs into the plasma membrane to stabilize the membrane. In line with this hypothesis, we have shown previously that the mHsp70 density increases after stress (Stangl et al. 2011; Murakami et al. 2015). Concomitantly, membrane-bound Hsp70 dissociates from the lipid raft component Gb3 and associates with the non-raft component phosphatidylserine (PS) (Schilling et al. 2009) that translocate from the inner to the outer plasma membrane leaflet. The elevated Hsp70 membrane expression density on tumor cells might be explained on the one hand by a stress-induced increase in the Hsp70 synthesis which results in an increased translocation of Hsp70 from the cytosol to PS in the plasma membrane, and on the other hand, by a fusion of Hsp70-containing nanotubes with the plasma membrane.

Author contributions M.S., J.R., G.D., and G.M. conceived the project. M.S. and J.R. performed the experiments. J.R. analyzed the data and performed the statistics. All authors wrote the manuscript, discussed results, and edited the manuscript.

Funding information The study was supported by the Alexander von Humboldt fellowship, by the grants of the Deutsche Forschungsgemeinschaft (DFG) SFB824/3, STA 1520/1-1, INST 411/37-1FUGG, INST 95/980-1FUGG, by the Bundesministerium für Bildung und Forschung (BMBF) 01GU0823, 02NUK038A, BMWi ZF4320102CS7, British Council Institutional Links grant (ID 277386067) under the Russia-UK partnership, Russian Science Foundation (14-50-00068), Federal Agency of Scientific Organizations in Russia, and by the cluster of excellence: Munich Advanced Photonics (MAP). 


\section{Compliance with ethical standards}

Competing interests The authors declare that they have no competing interests.

Publisher's Note Springer Nature remains neutral with regard to jurisdictional claims in published maps and institutional affiliations.

Open Access This article is distributed under the terms of the Creative Commons Attribution 4.0 International License (http:// creativecommons.org/licenses/by/4.0/), which permits unrestricted use, distribution, and reproduction in any medium, provided you give appropriate credit to the original author(s) and the source, provide a link to the Creative Commons license, and indicate if changes were made.

\section{References}

Ariazi J, Benowitz A, De Biasi V et al (2017) Tunneling nanotubes and gap junctions-their role in long-range intercellular communication during development, health, and disease conditions. Front Mol Neurosci 10:2120. https://doi.org/10.3389/fnmol.2017.00333

Bottanelli F, Kromann EB, Allgeyer ES, Erdmann RS, Wood Baguley S, Sirinakis G, Schepartz A, Baddeley D, Toomre DK, Rothmann JE, Bewersdorf J (2016) Two-colour live-cell nanoscale imaging of intracellular targets. Nat Comms 7:10778. https://doi.org/10.1038/ ncomms 10778

Dupont M, Souriant S, Lugo-Villarino G, Maridonneau-Parini I, Vérollet C (2018) Tunneling nanotubes: intimate communication between myeloid cells. Front Immunol 9:429. https://doi.org/10.3389/ fimmu.2018.00043

Gehrmann M, Liebisch G, Schmitz G, Anderson R, Steinem C, De Maio A, Pockles G, Multhoff G (2008) Tumor-specific Hsp70 plasma membrane localization is enabled by the glycosphingolipid Gb3. PLoS One 3:e1925. https://doi.org/10.1371/journal.pone.0001925

Gehrmann M, Kimm MA, Stangl S, Schmid TE, Noël PB, Rummeny EJ, Multhoff G (2015) Imaging of Hsp70-positive tumors with cmHsp70.1 antibody-conjugated gold nanoparticles. Int $\mathrm{J}$ Nanomed 10:5687-5700. https://doi.org/10.2147/IJN.S87174

Haimovich G, Ecker CM, Dunagin MC, Eggan E, Raj A, Gerst JE, Singer RH (2017) Intercellular mRNA trafficking via membrane nanotubes in mammalian cells. PNAS 114(46):E9873-E9882. https://doi.org/ 10.1073/pnas.1706365114

Hanahan D, Weinberg RA (2011) Hallmarks of cancer: the next generation. Cell 144:646-674. https://doi.org/10.1016/j.cell.2011.02.013

Hartl FU, Hayer-Hartl M (2002) Molecular chaperones in the cytosol: from nascent chain to folded protein. Science 295:1852-1858. https://doi.org/10.1126/science.1068408

Hell SW, Wichmann J (1994) Breaking the diffraction resolution limit by stimulated emission: stimulated-emission-depletion fluorescence microscopy. Opt Lett 19:780. https://doi.org/10.1364/OL.19. 000780

Koyanagi M, Brandes RP, Haendeler J, Zeiher AM, Dimmeler S (2005) Cell-to-cell connection of endothelial progenitor cells with cardiac myocytes by nanotubes: a novel mechanism for cell fate changes? Circ Res 96:1039-1041. https://doi.org/10.1161/01.RES. $0000168650.23479 .0 \mathrm{c}$

Kreyszig E (1974) Statistische methoden und ihre anwendung. Vandenhoek \& Ruprecht, Göttingen

Lou E, Gholami S, Romin Y, Thayanithy V, Fujisawa S, Desir S, Steer CJ, Subramanian S, Fong Y, Manova-Todorova K, Moore MAS (2017) Imaging tunneling membrane tubes elucidates cell communication in tumors. Trends in Cancer 3:678-685. https://doi.org/10.1016/j. trecan.2017.08.001

Marzo L, Gousset K, Zurzolo C (2012) Multifaceted roles of tunneling nanotubes in intercellular communication. Front Physiol 3:72. https://doi.org/10.3389/fphys.2012.00072

Mayer MP, Bukau B (2005) Hsp70 chaperones: cellular functions and molecular mechanism. CMLS 62:670-684. https://doi.org/10.1007/ s00018-004-4464-6

Multhoff G, Hightower LE (2011) Distinguishing integral and receptorbound heat shock protein 70 (Hsp70) on the cell surface by Hsp70specific antibodies. Cell Stress Chaperones 16:251-255. https://doi. org/10.1007/s12192-010-0247-1

Multhoff G, Botzler C, Wiesnet M, Müller E, Meier T, Wilmanns W, Issels RD et al (1995) A stress-inducible 72-kDa heat-shock protein (HSP72) is expressed on the surface of human tumor cells, but not on normal cells. Int J Cancer 61:272-279. https://doi.org/10.1002/ ijc. 2910610222

Murakami N, Kühnel A, Schmid TE, Ilicic K, Stangl S, Braun IS, Gehrmann M, Molls M, Itami J, Multhoff G et al (2015) Role of membrane Hsp70 in radiation sensitivity of tumor cells. Radiat Oncol 10:470. https://doi.org/10.1186/s13014-015-0461-1

Nimmervoll B, Chtcheglova LA, Juhasz K, Cremades N, Aprile FA, Sonnleitner A, Hinterdorfer P, Vigh L, Preiner J, Balogi Z (2015) Cell surface localised Hsp70 is a cancer specific regulator of clathrin-independent endocytosis. FEBS Lett 589:2747-2753. https://doi.org/10.1016/j.febslet.2015.07.037

Önfelt B, Nedvetzki S, Benninger RKP, Purbhoo MA, Sowinski S, Hume AN, Seabra MC, Neil MAA, French PMW, Davis DM (2006) Structurally distinct membrane nanotubes between human macrophages support long-distance vesicular traffic or surfing of bacteria. J Immunol 177:8476-8483. https://doi.org/10.4049/jimmunol.177. 12.8476

Osswald M, Jung E, Sahm F et al (2015) Brain tumour cells interconnect to a functional and resistant network. Nature 528:93-98. https://doi. org/10.1038/nature 16071

Reindl J, Drexler GA, Girst S, Greubel C, Siebenwirth C, Drexler SE, Dollinger G, Friedl AA (2015) Nanoscopic exclusion between Rad51 and 53BP1 after ion irradiation in human HeLa cells. Phys Biol 12:66005. https://doi.org/10.1088/1478-3975/12/6/066005

Reindl J, Girst S, Walsh DWM, Greubel C, Schwarz B, Siebenwirth C, Drexler GA, Friedl AA, Dollinger G (2017) Chromatin organization revealed by nanostructure of irradiation induced $\gamma \mathrm{H} 2 \mathrm{AX}, 53 \mathrm{BP} 1$ and Rad51 foci. Sci Rep 7:40616. https://doi.org/10.1038/ srep40616

Rustom A, Saffrich R, Markovic I, Walther P, Gerdes H-H (2004) Nanotubular highways for intercellular organelle transport. Science 303:1007-1010. https://doi.org/10.1126/science.1093133

Schilling D, Gehrmann M, Steinem C, De Maio A, Pockley AG, Abend M, Molls M, Multhoff G (2009) Binding of heat shock protein 70 to extracellular phosphatidylserine promotes killing of normoxic and hypoxic tumor cells. FASEB J 23:2467-2477. https://doi.org/10. 1096/fj.08-125229

Sherer NM (2013) Long-distance relationships: do membrane nanotubes regulate cell-cell communication and disease progression? Mol Biol Cell 24:1095-1098. https://doi.org/10.1091/mbc.e12-08-0622

Shevtsov M, Multhoff G (2016) Heat shock protein-peptide and HSPbased immunotherapies for the treatment of cancer. Front Immunol 7:171. https://doi.org/10.3389/fimmu.2016.00171

Shin BK, Wang H, Yim AM, Le Naour F, Brichory F, Jang JH, Zhao R, Purvas E, Tra J, Michael CW, MIsek DE Hanash SM (2003) Global profiling of the cell surface proteome of cancer cells uncovers an abundance of proteins with chaperone function. J Biol Chem 278: 7607-7616. https://doi.org/10.1074/jbc.M210455200

Simons K, Toomre D (2000) Lipid rafts and signal transduction. Nat Rev Mol Cell Biol 1:31-39. https://doi.org/10.1038/35036052 
Sowinski S, Jolly C, Berninghausen O, Purbhoo MA, Chauveau A, Köhler K, Oddos S, Eissmann P, Brodsky FM, Hopkins C, Önfelt B, Sattentau Q, Davis DM (2008) Membrane nanotubes physically connect $\mathrm{T}$ cells over long distances presenting a novel route for HIV1 transmission. Nat Cell Biol 10:211-219. https://doi.org/10.1038/ ncb1682

Specht HM, Ahrens N, Blankenstein C, Duell T, Fietkau R, Gaipl US, Günther C, Gunther S, Habl G, Hautmann H, Hautmann M, Huber RM, Molls M, Offner R, Rödel C, Rödel F, Schütz M, Combs SE, Multhoff G (2015) Heat shock protein 70 (Hsp70) peptide activated natural killer (NK) cells for the treatment of patients with non-small cell lung Cancer (NSCLC) after radiochemotherapy (RCTx) - from preclinical studies to a clinical phase II trial. Front Immunol 6:162. https://doi.org/10.3389/fimmu.2015.00162

Spötl L, Sarti A, Dierich MP, Möst J (1995) Cell membrane labeling with fluorescent dyes for the demonstration of cytokine-induced fusion between monocytes and tumor cells. J Int Soc Anal Cytol 21(2): 160-169. https://doi.org/10.1002/cyto.990210208

Stangl S, Gehrmann M, Dressel R, Alves F, Dullin C, Themelis G, Ntziachristos V, Staeblin E, Walch A, Winkelmann I, Multhoff G (2001) In vivo imaging of CT26 mouse tumours by using cmHsp70.1 monoclonal antibody. J Cell Mol Med 15:874-887. https://doi.org/10.1111/j.1582-4934.2010.01067.x

Stangl S, Themelis G, Friedrich L, Ntziachristos V, Sarantopoulos A, Molls M, Skerra A, Multhoff G (2011) Detection of irradiationinduced, membrane heat shock protein 70 (Hsp70) in mouse tumors using Hsp70 Fab fragment. Radiother Oncol 99:313-316. https:// doi.org/10.1016/j.radonc.2011.05.051

Stangl S, Varga J, Freysoldt B, Trajkovic-Arsic M, Siveke JT, Greten FR, Ntziachristos V, Multhoff G (2014) Selective in vivo imaging of tumors with a tumor cell-specific Hsp70 peptide-based probe. Cancer Res. https://doi.org/10.1158/0008-5472.CAN-14-0413

Stangl S, Tei L, De Rose F, Reder S, Martinelli J, Sievert W, Shevtsov M, Öllinger R, Rad R, Schwaiger M, D'Alessandria C, Multhoff G (2018) Preclinical evaluation of the Hsp70 peptide tracer TPPPEG24-DFO [89Zr] for tumor-specific PET/CT imaging. Cancer Res 78:6268-6281. https://doi.org/10.1158/0008-5472.CAN-180707

Thorsteinsdottir J, Stangl S, Fu P, Guo K, Albrecht V, Eigenbrod S, Erl J, Gehrmann M, Tonn J-C, Multhoff G, Schichor C (2017) Overexpression of cytosolic, plasma membrane bound and extracellular heat shock protein 70 (Hsp70) in primary glioblastomas. J Neuro-Oncol 135(3):443-452. https://doi.org/10.1007/s11060-0172600-z

Vicidomini G, Moneron G, Han KY, Wetphal V, Ta H, Reuss M, Engelhardt J, Eggeling C, Hell SW (2011) Sharper low-power STED nanoscopy by time gating. Nat Meth 8:571-573. https://doi. org/10.1038/nmeth.1624

Vignais M-L, Caicedo A, Brondello J-M, Jorgensen C (2017) Cell connections by tunneling nanotubes: effects of mitochondrial trafficking on target cell metabolism, homeostasis, and response to therapy. Stem Cells Int 2017:1-14. https://doi.org/10.1155/2017/6917941

Watkins SC, Salter RD (2005) Functional connectivity between immune cells mediated by tunneling nanotubules. Immunity 23:309-318. https://doi.org/10.1016/j.immuni.2005.08.009

Weil S, Osswald M, Solecki G, Grosch J, Jung E, Lemke D, Ratliff M, Hänggi D, Wick W, Winkler F (2017) Tumor microtubes convey resistance to surgical lesions and chemotherapy in gliomas. NeuroOncology 19:1316-1326. https://doi.org/10.1093/neuonc/nox070 